\title{
DYSPHAGIA AFTER LAPAROSCOPIC TOTAL FUNDOPLICATION: anterior or posterior gastric wall fundoplication?
}

\author{
Adorísio BONADIMAN ${ }^{1}$, Alexandre Chartuni Pereira TEIXEIRA², \\ Alberto GOLDENBERG ${ }^{2}$ and José Francisco de Mattos FARAH ${ }^{1}$
}

\begin{abstract}
Context - The occurrence of severe dysphagia after laparoscopic total fundoplication is currently an important factor associated with loss of quality of life in patients undergoing this modality of treatment for gastroesophageal reflux disease. $\mathrm{Objec}$ tive - Compare the incidence and evaluate the causes of severe postoperative dysphagia in patients undergoing laparoscopic total fundoplication (LTF) without short gastric vessels division, using the anterior gastric wall (Rossetti LTF) or anterior and posterior gastric walls (Nissen LTF). Methods - Analysis of the data of 289 patients submitted to LTF without short gastric vessels division from January 2004 to January 2012, with a minimum follow-up of 6 months. Patients were divided in Group 1 (Rossetti LTF $-\mathrm{n}=$ $160)$ and Group 2 (Nissen LTF $-\mathrm{n}=129)$. Results - The overall incidence of severe postoperative dysphagia was $3.11 \%(4.37 \%$ in group 1 and $1.55 \%$ in group $2 ; P=0.169$ ). The need for surgical treatment of dysphagia was $2.5 \%$ in group 1 and $0.78 \%$ in group $2(P=0.264)$. Distortions of the fundoplication were identified as possible causes of the dysphagia in all patients taken to redo fundoplication after Rossetti LTF. No wrap distortion was seen in redo fundoplication after Nissen LTF. Conclusion - The overall incidence of severe postoperative dysphagia did not differ on the reported techniques. Only Rossetti LTF was associated with structural distortion of the fundoplication that could justify the dysphagia.
\end{abstract}

HEADINGS - Gastroesophageal reflux. Fundoplication. Deglutition disorders.

\section{INTRODUCTION}

Laparoscopic total fundoplication (LTF) is a safe and effective method for the surgical treatment of gastroesophageal reflux (GERD). It provides good control of gastroesophageal reflux in the medium and long term ${ }^{(6,7,19,21)}$. However, the surgical approach of GERD is associated with several adverse effects, especially gas-bloating and dysphagia, that results in loss of quality of life and great dissatisfaction in significant proportion of patients ${ }^{(2,17)}$.

Several randomized studies and their metaanalyses have demonstrated that routine short gastric vessels (SGV) division is not necessary in LTF and is associated with a greater occurrence of complications. This maneuver, therefore, should be reserved for cases in which a floppy, tension-free, adequately positioned total fundoplication cannot be performed without this

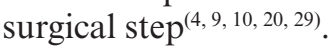

The LTF without SGV division may be performed using two different techniques. In the first, called Nissen LTF, the fundoplication is done with the anterior and posterior gastric walls after an extensive mobilization of the gastric fundus and a thorough retrogastric cavity dissection. In the other technique, called Rossetti LTF, the wrap is performed using only the anterior gastric wall, after extensive mobilization of the gastric fundus without accessing the retrogastric cavity $^{(10,22,28,31)}$. Other steps (esophageal dissection and hiatoplasty) are identical in both techniques.

Occurrence of mild and transient dysphagia is common in the early postoperative period, regardless of the type of surgical technique employed ${ }^{(24)}$. It usually resolves with a slowly progressive diet in a period of up to 6 weeks. Severe and persistent dysphagia, however, is usually related to surgical technique and requires, in addition to dietary adaptation, endoscopic intervention and/or surgery for resolution $^{(18,23,30,32)}$.

Some studies have reported a greater incidence of postoperative dysphagia in patients undergoing Rossetti LTF when compared to other techniques $^{(18,23)}$ The aim of this study was to compare the incidence and evaluate the possible causes of severe dysphagia after the performance of LTF without SGV division using only the anterior gastric wall (Rossetti LTF) or the anterior and posterior gastric walls (Nissen LTF). We also evaluated operative time and presence of perioperative complications in each group. 


\section{METHODS}

This is a retrospective study based on a prospectively kept database of patients operated by the same group of surgeons, from January 2004 to January 2012, in the Hospital do Servidor Público Estadual (HSPE) and private hospitals of São Paulo, Brazil. The study included patients undergoing primary LTF without SGV division with minimum follow-up of 6 months. We excluded data of patients with severe preoperative dysphagia, mixed hiatal or paraesophageal hernias, redo fundoplications, and those in which mesh reinforcement of the hiatoplasty was needed. The study was approved by the Ethics Committee in Research of the HSPE, registered under the number 01855412.0.0000.5463.

Two hundred eighty nine patients were selected, 160 (55\%) of which underwent Rossetti LTF (group 1) and 129 $(45 \%)$ Nissen LTF (group 2). The choice of the surgical technique was at the discretion of the main surgeon during the procedure.

There was no significant difference between the groups regarding age, gender, body mass index, presence of preoperative symptoms and Barrett esophagus. Although the prevalence of esophagitis was statistically higher in group 1 ( $71.9 \%$ vs $59.7 \%-P=0.029)$, there was no difference in the distribution of cases of severe esophagitis.

All included patients underwent a posterior hiatoplasty using one to three nonabsorbable figure-of-eight sutures as needed. In both groups, after extensive mobilization of the gastric fundus, total fundoplication, about $3 \mathrm{~cm}$ in length, was made with 3 nonabsorbable sutures, at least one of them (usually the intermediary) also set in the esophageal wall (Figure 1).

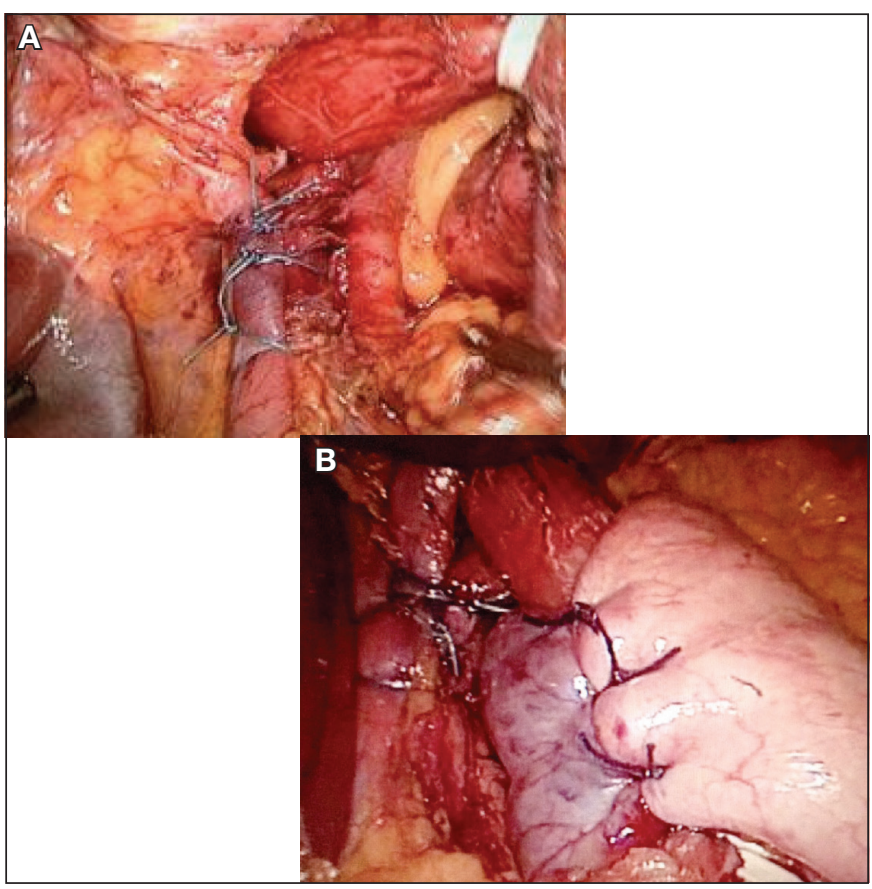

FIGURE 1. Hiatoplasty (A) and final aspect of LTF (B)
In group 1 (Rossetti LTF) a posterior total fundoplication was made using only the anterior wall of the gastric fundus on both sides (Figure 2). Patients of group 2 (Nissen LTF) were submitted to opening of the retrogastric cavity and thorough dissection of the posterior wall of the gastric fundus. The total valve was then performed with the anterior wall of the stomach on the left and its posterior counterpart on the right side of the esophagus (Figure 3). In both groups the correct position and tension of the valve was confirmed by the shoe-shine maneuver and the drop test ${ }^{(8)}$.

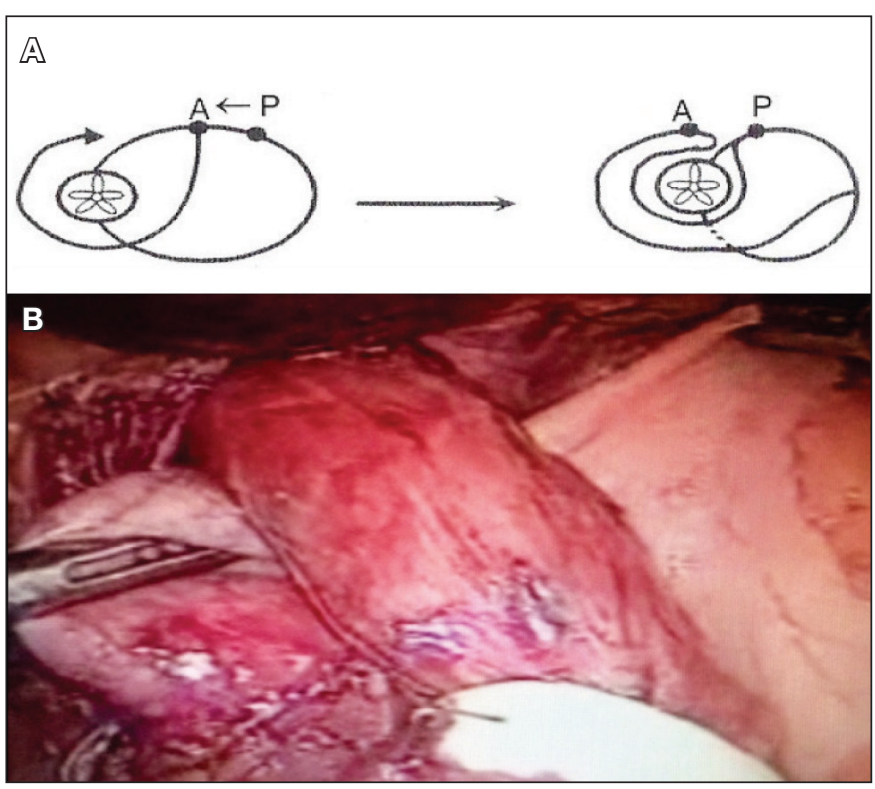

FIGURE 2. Schematic representation $(\mathrm{A})^{3}$ and photo (B) of the anterior wall of the gastric fundus preparing to Rossetti LTF

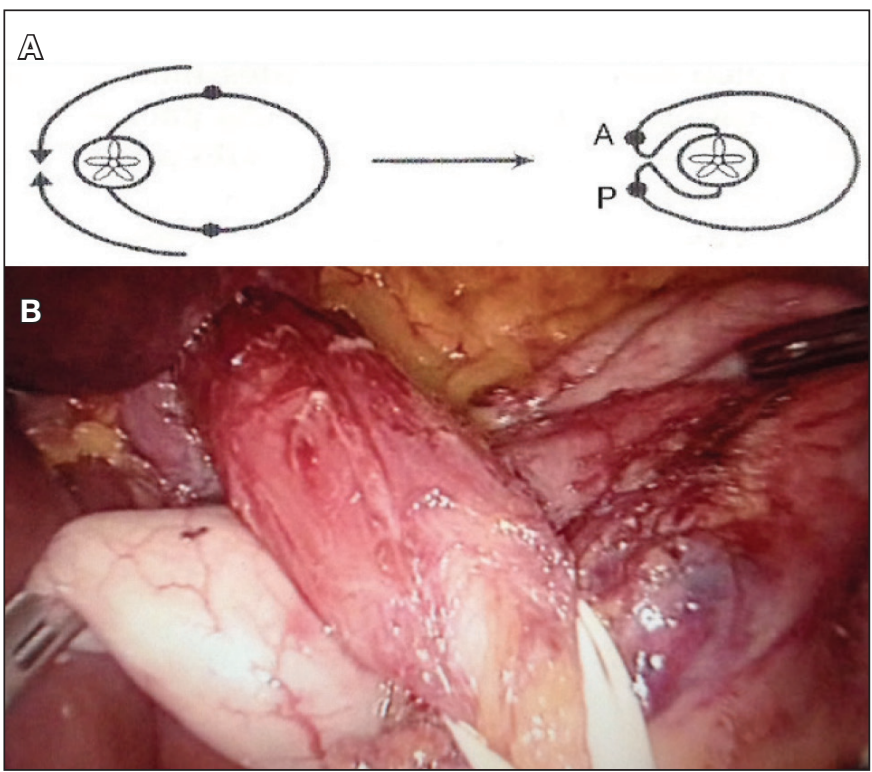

FIGURE 3. Schematic representation $(\mathrm{A})^{3}$ and photo (B) of the posterior and anterior wall of the gastric fundus preparing to Nissen LTF 
No bougies were used for "calibration" of the valve, regardless of the type of surgery. All patients received the same specific dietary orientation for the first month. Outpatient appointments were scheduled for 10,30,90 and 180 days postoperatively, and then annually. Upper digestive endoscopy was offered to all patients after the third postoperative month, regardless of the presence of symptoms. Other diagnostics tests were performed as required.

To evaluate postoperative dysphagia (primary outcome), the DeMeester dysphagia scale was used, as proposed by Gotley et al. ${ }^{(14)}$. Cases classified as grade 3 (Figure 4) were considered severe dysphagia. The modality of treatment for these cases (endoscopy dilation or surgery) and the intraoperative findings in those cases that needed surgery were noted. The operative time, morbidity and mortality were also analyzed.

\begin{tabular}{|c|l|}
\hline Degree & Definition \\
\hline 0 & Absence of dysphagia \\
1 & Occasional feeling of entrapment \\
2 & $\begin{array}{l}\text { Episodes of esophageal obstruction, requiring liquid to } \\
\text { lighten }\end{array}$ \\
3 & $\begin{array}{l}\text { Progressive dysphagia requiring medical attention or } \\
\text { complete esophageal obstruction. Need for endoscopic or } \\
\text { surgical intervention }\end{array}$ \\
\hline
\end{tabular}

FIGURE 4 . DeMeester scale for dysphagia

The ANOVA and the Equality of Two Proportions Tests were used for statistical analysis of quantitative and qualitative data, respectively. The technique of confidence interval for mean was used when indicated. A significance level of 0.05 was adopted. We used the software: SPSS V17, Minitab 16 and Office Excel 2010.

\section{RESULTS}

Of the 289 patients included in this study, $9(3.11 \%)$ had severe dysphagia. Seven of these patients were from group 1 (Rossetti LTF), comprising $4.37 \%$ of the group case load $(\mathrm{n}=160)$. Two had complete symptomatic relief after pneu- matic endoscopic dilation. However, four patients failed to achieve satisfactory improvement of symptoms after endoscopic dilation and surgical treatment was hence indicated. One patient refused endoscopic or operative treatment despite persistent dysphagia.

In group $2(n=129)$, severe dysphagia occurred in two patients $(1.55 \%)$. They underwent endoscopic pneumatic dilation, resulting in significant improvement of symptoms. In one patient, however, there was recurrence of dysphagia and no adequate response was observed after subsequent dilations. Surgical treatment was then performed. Table 1 shows the incidence of severe dysphagia and the need for surgical approach in groups 1 and 2 .

All patients from group 1 that needed reoperations $(n=4)$ had an anatomically incorrect and twisted fundoplication, all of them including part of the anterior wall of the gastric body. The reoperated patient from group 2 had no structural defect of the valve that could justify the dysphagia.

The mean operative time in group 1 was $90.3 \mathrm{~min}(30-180$ min) whereas in group 2 it was $101.3 \mathrm{~min}(45-240 \mathrm{~min})$, with $P=0.032$. Intraoperative complications occurred in 5 patients in group $1(3.13 \%)$ and in 3 patients in group 2 $(2.33 \%$ ) with $P=0.6$ (Table 2 ). There was no conversion to laparotomy or mortality in either group.

\section{DISCUSSION}

Severe and persistent postoperative dysphagia after LTF is the main cause of reoperations in GERD's surgical treatment, posing a major concern for the enthusiasts of this type of treatment $t^{2,12,17)}$ The proper investigation of this complication is mandatory for the adequate selection of the treatment. Well-positioned valves, without evidences of structural defects, can be adequately treated with endoscopic dilation as a first choice; nonetheless, patients with twisted, migrated or anatomically disrupted fundoplications rarely respond satisfactorily to endoscopic treatment and should be taken to early surgical correction ${ }^{(5)}$. It is worth noting that although some studies have reported satisfactory results after revisional laparoscopic fundoplication ${ }^{(11,25)}$ redo fundoplications usually have worse results than primary surgery ${ }^{(12,23)}$.

For the Nissen LTF, we realize an extensive mobilization of the gastric fundus, with opening and dissection of the

TABLE 1. Incidence of Severe dysphagia and need for reoperation

\begin{tabular}{lccccc}
\hline & N & Severe dysphagia $(\%)$ & $\boldsymbol{P}$-value & Reoperation $(\%)$ & $4(2.5)$ \\
\hline Group 1 & $7(4.38)$ & 0.169 & $1(0.78)$ & 0.264 \\
Group 2 & 160 & $2(1.55)$ & - & - & - \\
Total & 129 & $9(3.11)$ & - & & - \\
\hline
\end{tabular}

TABLE 2. Surgical Time, Complications and Mortality - Groups 1 and 2

\begin{tabular}{lccc}
\hline & Group 1 & Group 2 & $P$-value \\
\hline Mean operative time (variation) min & $90.3(30$ a 180) & $101.3(45$ a 240) & 0.032 \\
Complications $(\%)$ & $5(3.13)$ & $3(2.33)$ & 0.600 \\
Mortality & 0 & 0 & - \\
\hline
\end{tabular}


retrogastric cavity. This surgical step allows the use of the posterior gastric wall for the confection of the fundoplication. However, we did not perform routine division of SGV, as commonly advocated by others ${ }^{(26)}$. The non-systematic ligation of SGV is grounded in randomized studies ${ }^{(10,29)}$ and meta-analyzes ${ }^{(9,20)}$ that showed that this practice is not required to improve surgical outcomes and is related to longer surgical time and higher incidence of intraoperative and late complications or adverse effects, such as bleeding and flatulence, respectively. We also consider that in some situations ligation of the SGV may be mandatory (according to intraoperative evaluation of the tension of the fundoplication), but these patients were not included in this analysis. We have adopted a LTF without routine SGV division, as described by Farah et al. ${ }^{(10)}$ as the main procedure for the treatment of GERD.

In our series, the overall incidence of severe postoperative dysphagia was $3.11 \%$ (4.38\% in group 1 and $1.55 \%$ in group $2, P=0.169)$. Surgical treatment of dysphagia was needed in $2.5 \%$ of patients of group 1 and $0.78 \%$ at group 2 , with $P=0.264$ (Table 1).

We found that the incidence of severe dysphagia in our study follows the trends of international reports, regardless of the technique used. Amato et al. reported the occurrence of severe dysphagia in $1.4 \%$ of patients after LTF in a series of 102 patients $^{(1)}$ In a recent European study, prospective and randomized, comparing the results of medical and surgical treatment of GERD, Galmiche et al. found $11 \%$ of disphagia after laparoscopic fundoplication ${ }^{(13)}$. For Richter et al. about $3 \%-24 \%$ of patients develop persistent dysphagia after LTF $^{(24)}$. Stewart et al reported that the surgeon's experience with the operative technique is a key factor in the outcomes of surgical treatment of GERD ${ }^{(27)}$. We believe that technical standardization is the most important factor for the outcome evaluated in this study. It is noteworthy that many patients, in different medical institutions, are treated by less experienced surgeons and conducting practical and reproducible tactics are critical to the outcome. We emphasize that a considerable proportion of our patients were operated by training surgeons (residents under supervision) with different levels of expertise, suggesting that the employed tactics can be repeated accurately.

The Rossetti LTF has been associated with higher incidence of postoperative dysphagia by some authors. Hunter et al. found moderate to severe dysphagia persisted after 3 months in $11 \%$ of patients submitted by Rossetti LTF and $2 \%$ by Nissen or Toupet $\operatorname{LTF}^{(18)}$. Patti et al. reported $14 \%$ of dysphagia after Rossetti LTF, while only $6 \%$ of patients had dysphagia after Nissen LTF $^{(23)}$. In our study, although we did not find statistical differences in the incidence of severe dysphagia between groups, the intraoperative findings during reoperations were distinct. In all reoperated patients after Rossetti LTF there were twisted valves involving the gastric body (not just the fundus, as recommended), with obvious structural abnormality. This corresponds to a type III alteration, as described by Horgan ${ }^{(16)}$ in which the most common manifestation is dysphagia ${ }^{(15,16)}$. Thus, a new total fundoplication involving the anterior and posterior gastric walls, adequately positioned, and was used by us for treating dysphagia in two cases. In the two other cases we chose a partial valve due to the low pressure of the body of the esophagus at manometry. On the other hand, the only patient that underwent reoperation after Nissen LTF did not have any anatomical disruption, and this complication was treated with a partial valve.

The importance of these facts certainly transcends the simple report of an intraoperative finding. We believe that Nissen LTF, by exposing the retrogastric cavity and permitting the use of the posterior gastric wall facilitates the adequate positioning of a floppy fundoplication, using only the gastric fundus. On the other hand, in the Rossetti LTF we would be prone to perform technically misplaced wraps, with excessive tension or involving the anterior wall of the gastric body. These details are very important for less experienced surgeons: when facing difficulties for performing a floppy fundoplication they can, by mistake, involve the gastric body in the formation of the valve, setting up a serious technical error.

The operative time was longer in group 2, where we found mean time of $101.3 \mathrm{~min}(45-240 \mathrm{~min})$, whereas in group 1 it was $90.3 \mathrm{~min}(30-180 \mathrm{~min})$, with $P=0.032$. Hunter et al. ${ }^{(18)}$ also reported a higher surgical time in performing the Nissen LTF regarding the Rossetti LTF. But, for Hunter, the SGV division was performed routinely, justifying the longer surgical time after the Nissen LTF. We believe that greater operative time for Nissen LTF in our series was due mainly to the time spent for the dissection of the retrogastric cavity and adequate exposure of the posterior gastric wall.

However, the greater operative time required for performing the Nissen LTF was not followed by an increased rate of perioperative complications. In group 1 we observed 3.13\% of complications (subcutaneous emphysema and hypercapnia), while in group 2 these were observed in $2.33 \%$ of patients (perforation of the pleura, hypercapnia and gastric wall hematoma), with $P=0.6$ (Table 2 ). We did not observe major complications or mortality in either group, which demonstrates that the LTF is a safe procedure, with a low complication rate, regardless of the employed technique.

This study has methodological limitations. It is retrospective, with data collected from a database adopted in our service. Furthermore, the choice of the surgical technique used in each case was not random and one could assume that more extensive mobilization occurred in the most difficult cases. Beyond that, we didn't evaluate long term results of GERD or others outcomes. However, when we analyze the demographic data in each group, we notice that there were no significant differences. Therefore, the findings obtained allow us to safely evaluate the results of the surgical techniques presented. Future studies with larger numbers of patients and with different methodological criteria (specially randomized and prospective) will help to confirmed Nissen LTF best choice for laparoscopic total fundoplication without short gastric vessels division. 


\section{CONCLUSION}

The incidence of severe postoperative dysphagia was low and showed no statistically significant difference between the two reported techniques. The common finding in all reoperations for dysphagia after Rossetti LTF was an structural incorrect valve, involving the gastric body in its confection. No structural alterations were observed at the reoperation for dysphagia after Nissen LTF. Although involving greater operative time, the Nissen LTF was not associated with a higher incidence of perioperative complications.

Bonadiman A, Teixeira ACP, Goldenberg A, Farah JFM. Disfagia após fundoplicatura total laparoscópica: válvula com a parede gástrica anterior ou posterior? Arq Gastroenterol. 2014,51(2):113-17.

RESUMO - Contexto - A ocorrência de disfagia grave após fundoplicatura total laparoscópica representa atualmente um importante fator associado à perda da qualidade de vida em pacientes submetidos a esta modalidade de tratamento para doença do refluxo gastroesofágico. Objetivo - Comparar a incidência e avaliar as possíveis causas da disfagia grave pós-operatória em pacientes submetidos à fundoplicatura total laparoscópica (FTL) sem liberação dos vasos gástricos curtos utilizando apenas a parede gástrica anterior (FTL à Rossetti) ou as paredes gástricas anterior e posterior (FTL à Nissen). Métodos - Análise de dados de 289 pacientes submetidos à FTL sem liberação dos vasos gástricos curtos no período de janeiro de 2004 a janeiro de 2012, com acompanhamento mínimo de 6 meses. Os pacientes foram divididos em Grupo 1 (FTL à Rossetti $-\mathrm{n}=160)$ e Grupo $2(\mathrm{FTL}$ à Nissen $-\mathrm{n}=129)$. Resultados - A incidência global de disfagia grave pós-operatória foi de 3,11\%, sendo $4,37 \%$ no grupo 1 e $1,55 \%$ no grupo $2(P=$ 0.169). A necessidade de tratamento cirúrgico da disfagia foi de $2,5 \%$ no grupo 1 e $0,78 \%$ no grupo $2(P=0.264)$. Em todos os pacientes reoperados após FTL à Rossetti foram observadas distorções das válvulas que podem responder pela ocorrência de disfagia, ao passo que no paciente submetido à reoperação após FTL à Nissen nenhuma alteração foi observada. Conclusão - A incidência global de disfagia grave pós-operatória não apresentou diferença entre as duas técnicas relatadas. A FTL à Rossetti foi associada a distorções estruturais das válvulas que podem justificar a disfagia, fato não observado após FTL à Nissen.

DESCRITORES - Refluxo gastroesofágico. Fundoplicatura. Transtornos de deglutição.

\section{REFERENCES}

1. Amato G, Limongelli P, Pascariello A, Rossetti G, Del Genio G, Del Genio A, et al. Association between persistent symptoms and long-term quality of life after laparoscopic total fundoplication. Am J Surg. 2008;196:582-6.

2. Beenen E, Fogarty P, Roberts RH. Predicting patient dissatisfaction following laparoscopic Nissen fundoplication: an analysis of symptoms. Surg Endosc. 2013;27:1579-86.

3. Campos GMR, DeMeester TR. Doença do refluxo gastroesofágico-Análise crítica do tratamento cirúrgico. In: Gama-Rodrigues JJ, Del Grande JC, Martinez JC, editors. Tratado de Clínica Cirúrgica do Aparelho Digestório. São Paulo: Atheneu. 2004. p. 275-84.

4. Catarci M, Gentileschi P, Papi C, Carrara A, Marrese R, Gaspari AL, et al. Evidence-based appraisal of antireflux fundoplication. Ann Surg. 2004;239:325-37.

5. Chukwumah CV, Ponsky JL. Revisional surgery for failed antireflux surgery. Surg Laparosc Endosc Percutan Tech. 2010;20:326-31.

6. Dallemagne B, Perretta S. Twenty years of laparoscopic fundoplication for GERD. World J Surg. 2011;35:1428-35.

7. Davis CS, Baldea A, Johns JR, Joehl RJ, Fisichella PM. The evolution and longterm results of laparoscopic antireflux surgery for the treatment of gastroesophageal reflux disease. JSLS. 2010;14:332-41.

8. Davis RE, Awad ZT, Filipi CJ. Technical factors in the creation of a "floppy" Nissen fundoplication. Am J Surg. 2004;187:724-7.

9. Engström C, Jamieson GG, Devitt PG, Watson DI. Meta-analysis of two randomized controlled trials to identify long-term symptoms after division of the short gastric vessels during Nissen fundoplication. Br J Surg. 2011;98:1063-7.

10. Farah JF, Grande JC, Goldenberg A, Martinez JC, Lupinacci RA, Matone J. Randomized trial of total fundoplication and fundal mobilization with or without division of short gastric vessels: a short-term clinical evaluation. Acta Cir Bras. 2007;22:422-9.

11. Frantzides CT, Madan AK, Carlson MA, Zeni TM, Zografakis JG, Moore RM, Meiselman M, Luu M, Ayiomamitis GD. Laparoscopic revision of failed fundoplication and hiatal herniorraphy. J Laparoendosc Adv Surg Tech A. 2009;19:135-9.

12. Furnée EJ, Draaisma WA, Broeders IA, Gooszen HG. Surgical reintervention after failed antireflux surgery: a systematic review of the literature. J Gastrointest Surg. 2009;13:1539-49.

13. Galmiche JP, Hatlebakk J, Attwood S, Ell C, Fiocca R, Eklund S, et al. Laparoscopic antireflux surgery vs. esomeprazole treatment for chronic GERD: the LOTUS randomized clinical trial. JAMA. 2011;305:1969-77.

14. Gotley DC, Smithers BM, Menzies B, Branicki FJ, Rhodes M, Nathanson L. Laparoscopic Nissen fundoplication and postoperative dysphagia - can it be predicted? Ann Acad Med Singapore. 1996;25:646-9.

15. Hatch KF, Daily MF, Christensen BJ, Glasgow RE. Failed fundoplications. Am J Surg. 2004;188:786-91.
16. Horgan S, Pohl D, Bogetti D, Eubanks T, Pellegrini C. Failed antireflux surgery: what have we learned from reoperations? Arch Surg. 1999;134:809-15.

17. Humphries LA, Hernandez JM, Clark W, Luberice K, Ross SB, Rosemurgy AS. Causes of dissatisfaction after laparoscopic fundoplication: the impact of new symptoms, recurrent symptoms, and the patient experience. Surg Endosc. 2013;27:1537-45.

18. Hunter JG, Swanstrom L, Waring JP. Dysphagia after laparoscopic antireflux surgery. The impact of operative technique. Ann Surg. 1996;224:51-7.

19. Lundell L. Surgical therapy of gastro-oesophageal reflux disease. Best Pract Res Clin Gastroenterol. 2010;24:947-59.

20. Markar SR, Karthikesalingam AP, Wagner OJ, Jackson D, Hewes JC, Vyas S, et al. Systematic review and meta-analysis of laparoscopic Nissen fundoplication with or without division of the short gastric vessels. Br J Surg. 2011;98:1056-62.

21. Neri V, Ambrosi A, Di Lauro G, Fersini A, Valentino TP. Indications for the laparoscopic treatment of gastroesophageal reflux disease. JSLS. 2005;9:68-72.

22. Nissen R. Eine einfache Operation zur Beeinflussung der Refluxeosophagitis Schweiz Med Wochenschr. 1956;86:590-2.

23. Patti MG, Arcerito M, Feo CV, De Pinto M, Tong J, Gantert W, et al. An analysis of operations for gastroesophageal reflux disease: identifying the important technical elements. Arch Surg. 1998;133:600-6

24. Richter JE. Gastroesophageal reflux disease treatment: side effects and complications of fundoplication. Clin Gastroenterol Hepatol. 2013;11:465-71.

25. Serafini FM, Bloomston M, Zervos E, Muench J, Albrink MH, Murr M, Rosemurgy AS. Laparoscopic revision of failed antireflux operations. J Surg Res. 2001;95:13-8.

26. Smith CD. Surgical therapy for gastroesophageal reflux disease: indications, evaluation, and procedures. Gastrointest Endosc Clin N Am. 2009;19:35-48.

27. Stewart GD, Watson AJ, Lamb PJ, Lee AJ, Krukowski ZH, Griffin SM, et al Comparison of three diferente procedures for antireflux surgery. Br J Surg. 2004;91:724-9.

28. Stylopoulos N, Rattner DW. The history of hiatal hernia surgery: from Bowditch to laparoscopy. Ann Surg. 2005;241:185-93.

29. Yang H, Watson DI, Lally CJ, Devitt PG, Game PA, Jamieson GG. Randomized trial of division versus nondivision of the short gastric vessels during laparoscopic Nissen fundoplication: 10-year outcomes. Ann Surg. 2008;247:38-42.

30. Waring JP. Postfundoplication complications. Prevention and management. Gastroenterol Clin North Am. 1999;28:1007-19.

31. Watson DI. Nissen-Rossetti antireflux fundoplication (open procedure). In: Fischer JE, Bland KI, Callery MP, Clagett GP, Jones DB, LoGerfo FW, Seeger JM, editors. Mastery of Surgery. Philadelphia: Lippincott Williams e Wilkins; 2007. p. 704-11.

32. Wilshire CL, Niebisch S, Watson TJ, Litle VR, Peyre CG, Jones CE, et al. Dysphagia postfundoplication: more commonly hiatal outflow resistance than poor esophageal body motility. Surgery. 2012;152:584-92.

Received 29/10/2013 Accepted 6/3/2014 